SISTEMA
ELETRONNICO
DE REVISTAS
SER I UFPR

\title{
Análise da vulnerabilidade populacional aos riscos tecnológicos ambientais na área urbana da cidade de Manaus-AM
}

\section{Analysis of population vulnerability to environmental technological risks in the urban area of the city of Manaus-AM}

\author{
Alexandre Araújo de OLIVEIRA ${ }^{1 *}$, João Tito BORGES ${ }^{2}$ \\ ${ }^{1}$ Universidade Federal de Mato Grosso do Sul (UFMS), Campo Grande, MS, Brasil. \\ ${ }^{2}$ Universidade Federal do Amazonas (UFAM), Manaus, AM, Brasil. \\ *E-mail de contato: engamb.alexandrearaujo@gmail.com
}

Artigo recebido em 3 de maio de 2018, versão final aceita em 27 de agosto de 2018.

RESUMO: $\quad$ Este trabalho procura identificar e caracterizar a situação de vulnerabilidade populacional aos riscos tecnológicos ambientais nos bairros da área urbana de Manaus-AM, Brasil. As fontes geradoras desses riscos, identificadas e caracterizadas como ameaças que tenham potencial de causar algum dano foram: termelétricas, indústrias que utilizam solventes e/ou gases, áreas portuárias, áreas de disposição de resíduos, áreas aeroportuárias e depósito de combustíveis. A elaboração da base de dados foi realizada por meio do levantamento de informações disponibilizadas pelos órgãos locais, federais e agências nacionais; trabalho de campo, a fim de certificar a operação das fontes geradoras de risco; e uso de Sistema de Informação Geográfica. Os bairros da cidade de Manaus foram classificados em cinco categorias de vulnerabilidade, resultantes da combinação de três dimensões: densidade populacional; Índice de Desenvolvimento Humano Municipal - Dimensão Renda; e ocorrência de fatores geradores de risco. Os resultados apontam que os fatores de risco tecnológico estão concentrados na região sul da cidade, embora os bairros que apresentam maior ocorrência de fatores de risco estejam situados nas zonas norte e leste, zonas que também apresentam os piores IDH. A distribuição da população concentra-se no eixo nordeste-sudoeste, com destaque para os bairros a sudoeste, onde localizam-se os bairros mais antigos e o centro histórico da capital. Os níveis mais elevados de vulnerabilidade encontram-se na região nordeste, onde estão localizados bairros de condições socioeconômicas precárias e muito povoados. Este trabalho, nesse sentido, ao identificar e caracterizar as áreas críticas de vulnerabilidade e de concentração de fatores de risco tecnológico, traz subsídios relevantes para o planejamento de políticas públicas e desenvolvimento de estratégias para a prevenção de riscos e danos à saúde da população. Os resultados expõem cenários que devem ser alvos de políticas direcionadas à redução das problemáticas, podendo e devendo ser o planejamento urbano uma ferramenta para atenuar esses níveis. 
Palavras-chaves: vulnerabilidade populacional; riscos tecnológicos ambientais; Amazônia; Manaus.

ABSTRACT: This work aims to identify and characterize the situation of population vulnerability to environmental technological risks for the neighborhoods of the urban area of Manaus - state of Amazonas, Brazil. The sources of these risks, identified and characterized as potentially damaging threats were: thermoelectric, solvent and/or gas industries, port areas, waste disposal areas, airport areas and fuel depots. The elaboration of the database was done through the collection of information made available by local, federal and national agencies; field work to certify the operation of the sources of risk; and use of Geographic Information System. The neighborhoods of the city of Manaus were classified into five vulnerability categories, resulting from the combination of three dimensions: population density; Municipal Human Development Index - Income Dimension; and occurrence of risk factors. The results indicate that the technological risk factors are concentrated in the southern region of the city, though the neighborhoods with the highest incidence of risk factors are located on the north and east zones, areas that also have the worst HDI. The distribution of the population is concentrated in the northeast-southwest axis, highlighting the neighborhoods to the southwest, where the oldest neighborhoods and the historical center of the capital are located. The highest levels of vulnerability are found in the northeastern region, where neighborhoods of precarious socioeconomic conditions and highly populated are located. This work, when identifying and characterizing critical areas of vulnerability and concentration of technological risk factors, provides relevant subsidies for the planning of public policies and development of strategies for the prevention of risks and damages to population's health. The results show scenarios that should be the targets of policies aimed at reducing the problems, urban planning can and should be a tool to reduce these levels.

Keywords: population vulnerability; environmental technological risks; Amazonia; Manaus.

\section{Introdução}

Com a criação da Zona Franca de Manaus, através do Decreto-Lei 288 (Brasil, 1967), a qual estimulou a industrialização na cidade, diversas empresas e milhares de pessoas do Brasil e do mundo foram atraídas para a região. De acordo com dados do IBGE (1970), a população, que era de 314.197 habitantes em 1970, em 2010, passou a ser de 1.802.014 habitantes (IBGE, 2010), fato que comprova esse rápido e intenso crescimento.

Aproveitando os benefícios do desenvolvimento das cidades, essas crescentes populações estão cada vez mais familiarizadas com os meios tecnológicos, e muitas vezes não conseguem mais viver sem eles, pois essas tecnologias dispõem de facilidades de produção, uso de diferentes meios de transporte e equipamentos tecnológicos, proporcionando facilidades na vida urbana.

Entretanto, como custo desses benefícios, a humanidade se defronta com a ampliação de potencialidades que ameaçam constantemente a nossa saúde e o meio ambiente. Os equipamentos que facilitam nossas vidas também nos deixam expostos aos chamados riscos tecnológicos ambientais. Estes, por sua vez, estão associados ao crescente processo de industrialização em que, ao lado dos processos de produção e seus produtos, têm contribuído para colocar em perigo ou causar prejuízos à saúde do homem e dos ecossistemas (Brilhante \& Caldas, 1999).

Os riscos podem gerar dois tipos de poluição: a crônica (fenômeno perigoso que ocorre de forma recorrente, às vezes lenta e difusa) e a aguda (explosões, vazamento de produtos tóxicos, incêndios). 
A combinação de frequência e consequência de um evento não desejável relacionado aos riscos tecnológicos pode causar perdas humanas, materiais e ambientais, e advém de várias ações em que ocorre a interferência do homem, como potenciais acidentes industriais vindouras do transporte por via aérea, naval e rodoviária, ou adução de substâncias perigosas dos gasodutos, oleodutos e distribuidores de solventes entre empresas diferentes; decorrente de interações entre sistemas sociais e sistemas e estruturas artificiais, como barragens, diques, estruturas portuárias, redes urbanas de telecomunicações, energia e de transporte; e sistemas de disposição ou tratamento de resíduos, como aterros e incineradores.

Esses eventos não desejáveis ou acidentes tecnológicos estão diretamente relacionados com a crescente demanda por novos materiais e produtos químicos, verificados desde a mudança da base produtiva do carvão para o petróleo. Soma-se a isso a maximização da produção inserida no contexto de um comércio globalizado e de acirrada concorrência entre as corporações, o que leva ao aumento da produção, armazenamento e transporte de substâncias e materiais nocivos ao homem e ao meio ambiente, e consequentemente, ao aumento da exposição a eles, sobretudo nas comunidades próximas às instalações que manuseiam tais substâncias e produtos, além dos próprios trabalhadores dessas unidades (Rocha Jr. et al., 2006).

De acordo com dados globais do EM-DAT (The Internacional Disaster Database), nas últimas décadas, foi registrado o maior número de ocorrências de desastres tecnológicos, sendo o Brasil o país do continente americano com o maior número de pessoas afetadas por eventos de ordem natural, social e/ou tecnológica.
Segundo a UNISDR (2004), a razão para o número de mortes decorrentes dos acidentes tecnológicos é simples e ao mesmo tempo complexa, e está relacionada ao modo de como as pessoas e as sociedades estão se tornando mais vulneráveis, em que as atividades humanas têm contribuído para a intensificação dos danos que tais eventos ocasionam. O uso de práticas não sustentáveis de desenvolvimento, o crescimento desordenado das cidades e a má distribuição de renda são algumas das causas desse processo.

Assim, os estudos sobre percepção de riscos iniciaram-se no final dos anos 1970 e começo dos anos 1980, devido à grande importância de se ter conhecimento sobre eles, representando uma crítica à perspectiva utilitarista e ao paradigma do ator racional como a concepção de democracia (Carmo \& Rocha, 2005).

Nesse processo, principalmente os especialistas das indústrias e do governo começaram a desenvolver e aplicar métodos científicos para estimar os riscos de modo quantitativo e probabilístico (Renn, 1985). Por um lado, desenvolveram-se os testes de laboratório, métodos epidemiológicos, modelagens ambientais, simulações em computadores e avaliações de riscos na engenharia, que possibilitaram o incremento na identificação e mensuração dos riscos, e permitiram aos cientistas detectar falhas em projetos de sistemas de engenharia extremamente complexos, bem como estabelecer nexos causais entre determinados perigos e resultados adversos, mesmo os potencialmente causados por quantidades de substâncias carcinogênicas ou mutagênicas muitíssimo pequenas, tal como partes por trilhão (Covello \& Mumpower, 1985; Renn, 1992). Por outro, cresceu o número de especialistas que passaram a ter como foco principal de seu trabalho 
os riscos à saúde, à segurança industrial e ao meio ambiente, contribuindo, assim, para a profissionalização e institucionalização da análise de riscos, com sociedades próprias, reuniões anuais, livros, periódicos científicos e newsletters. Um marco desse processo foi a formação, em 1980, da Sociedade Internacional para Análise de Riscos (Otway, 1985).

Os métodos sistêmicos de análises de riscos desenvolvidos vêm sendo aplicados nas indústrias de processos, como é o caso das químicas de transformação, basicamente como ferramentas para a decisão acerca da aceitabilidade de uma nova planta industrial e para a melhoria da confiabilidade dos sistemas técnico e organizacional existentes. Segundo a UNISDR (2004), os resultados de tais métodos servem para decidir sobre: (a) a localização geográfica dos processos e operações industriais perigosas; (b) os investimentos nos equipamentos voltados à prevenção de acidentes e limitação de suas consequências; (c) os projetos tecnológicos de processos de fabricação e sistemas de controle; (d) a criação de rotinas operacionais e de manutenção; e (e) a elaboração de documentos de segurança para a organização.

Dessa forma, diante do fato de que a população tem o direito de saber os tipos de riscos aos quais está sujeita, dada à gravidade e extensão dos danos que os acidentes tecnológicos ambientais podem proporcionar à saúde humana e ao ambiente, surge a ideia de espacializar e quantificar os diferentes níveis de riscos tecnológicos existentes na área urbana da cidade de Manaus-AM.

A avaliação e o gerenciamento de riscos têm sido importantes atividades atuais de cientistas, políticos, órgãos reguladores e do público em geral. Isto decorre não apenas do aumento da sensibilização da população, mas também da complexidade dos impactos relacionados aos riscos, os quais abrangem aspectos ainda pouco conhecidos na ciência atual. A busca de soluções desses problemas tem envolvido as mais diversas áreas do conhecimento científico.

O Ministério do Meio Ambiente (Brasil, 2006) adota que o risco pode ser entendido como o potencial de ocorrência de consequências indesejadas oriundas da realização de uma atividade. A definição do risco inclui, ainda, as características do local onde mora o perigo: densidade; modo de urbanização e de organização das redes; e fluxos de circulação. É uma consequência adversa de eventos indesejados à vida humana ou ao meio ambiente, seja interno (uma indústria, por exemplo) ou externo. $\mathrm{O}$ risco, no que the concerne, pode ser classificado de acordo com o tipo de atividade, exposição (instantânea ou crônica), probabilidade de ocorrência, severidade, reversibilidade, visibilidade, duração e consequências de seus efeitos, ocorrendo num período específico.

De um modo geral, todas as definições objetivas de risco parecem concordar que, para a caracterização de um risco, é necessária a existência simultânea de uma "fonte" (perigo) e um "sujeito" (o ser humano ou qualquer outro elemento de um ecossistema que esteja exposto ao perigo).

Dagnino \& Capri Junior (2007, p. 50) definem risco como: "[...] a probabilidade de que um evento - esperado ou não esperado - se torne realidade. A ideia de que algo pode vir a ocorrer, já então configura um risco." Assim, a presença de um fator que possa desencadear uma situação que coloque em perigo ou cause prejuízos ao homem e/ou ao ambiente é um risco, mesmo que eventos relacionados a esses fatores nunca tenham sido 
observados em determinada localidade, bastando, então, que a sociedade identifique e reconheça o perigo para que se determine a existência do risco.

Os riscos podem ser classificados e conceituados com muitas qualificações provenientes de diversas fontes. Nesse sentido, na visão de Egler (1996, p. 31-40), aceita e utilizada por diversos autores, é importante que se considere o conceito de risco ambiental como o resultante de três categorias básicas: risco natural, associado ao comportamento dinâmico dos sistemas naturais; risco tecnológico, definido como o potencial de ocorrência de eventos danosos à vida, a curto, médio e longo prazo, em consequência das decisões de investimento na estrutura produtiva; e risco social, visto como resultante das carências sociais ao pleno desenvolvimento humano, que contribuem para a degradação das condições de vida.

Os riscos naturais estão associados aos eventos físicos da dinâmica terrestre, cujas ocorrências independem da vontade e do controle humano. Para Veyret \& Richemond (2007), os riscos naturais são aqueles pressentidos, percebidos e suportados por um grupo social ou um indivíduo sujeito à ação possível de um processo físico de uma área. Como exemplos de riscos naturais, podem ser citados os desmoronamentos, vulcanismos, ciclones, tempestades, inundações, nevascas, avalanches, secas, entre outros.

Já os riscos tecnológicos referem-se aos prejuízos resultantes das atividades produtivas, relacionados a todo tipo de tecnologia. Em acordo com Sevá Filho (1988, p. 81), a abordagem desse tipo deve levar em conta três fatores indissociáveis: “o processo de produção (recursos, técnicas, equipamentos, maquinário); o processo de trabalho (relações entre direções empresariais e estatais, e assalariados); e a condição humana (existência individual e coletiva; ambiente)".

$\mathrm{E}$, finalmente, os riscos sociais, que compreendem a insegurança incidente sobre as populações devido ao mau funcionamento das estruturas sociais. Fernandes \& Rocha (2007) citam que os riscos sociais compreendem os roubos a transeuntes, veículos e residência, além de guerras e terrorismo geral.

Independentemente do tipo do risco, seja ele natural, tecnológico ou social, o fato é que nas grandes cidades, sobretudo nos países pobres, esses riscos encontram um cenário propício para requererem muita atenção, pois a desigualdade social, a falta de recursos por parte dos gestores públicos e a ausência de leis de proteção ambiental e fiscalização do setor produtivo fazem aumentar as possibilidades de ocorrência de eventos danosos e também os prejuízos decorrentes destes.

Segundo Lavell (2000), o risco constitui uma condição latente para a sociedade. Representa a probabilidade de danos, os quais, se alcançarem certo nível, que é socialmente determinado, passam a ser conhecidos como "desastres". O risco, que é inerente à vida no planeta, é formado pela interação em um tempo e espaço específicos, de dois fatores: as ameaças e as vulnerabilidades.

A capacidade preventiva e respostas dos países têm sido inibidas pela falta de desenvolvimento institucional e pela não aplicação de instrumentos dentro de um contexto de prevenção e gestão antecipada do risco. O paradigma imperante está orientado para o desenvolvimento de planos de contingência para responder emergências: esses planos se aplicam invariavelmente sobre os efeitos e não sobre as causas. A carência de vínculos entre o planejamento do desenvolvimento, o uso do terri- 
tório, seus recursos e a gestão do risco conformam um panorama que reforça o círculo vicioso dos desastres (Castro, 2001).

Uma das tarefas mais importantes para as pesquisas de risco é dar suporte aos tomadores de decisões com critérios e processos tão claros e precisos quanto possíveis. Esses critérios são fundamentais para a elaboração de políticas de gerenciamento dos riscos.

Tendo em vista essa abordagem, é preciso que os órgãos de controle ambiental e órgãos ligados à defesa civil possam proporcionar a informação para a comunidade sobre os possíveis riscos e desenvolver, com base nessa informação, planos de atendimento para situações em que ocorram acidentes tecnológicos. De acordo com os princípios guias da OECD (2003) para a prevenção, preparação e resposta às emergências e aos desastres químicos, são responsabilidades e funções das autoridades públicas: motivar a todos os setores da sociedade sobre a importância das ações de prevenção, preparação e resposta às emergências e aos desastres químicos; estabelecer objetivos de segurança e garantir que sejam atingidos; definir uma estrutura de controle clara e coerente; monitorar a segurança em instalações perigosas; incentivar a pesquisa e a elaboração de relatórios de emergências e desastres, bem como gerar e implementar os meios que facilitem seu desenvolvimento; estabelecer procedimentos apropriados para avaliação dos impactos ambientais das instalações perigosas a serem construídas; defender o "direito da comunidade ao conhecimento", para garantir acesso à informação apropriada sobre as instalações perigosas ao público que possa ser potencialmente afetado; criar programas de preparação para as emergências, incluindo a realização de exercícios simulados; propiciar o desenvolvimento, a implementação, o teste e a atualização de planos de emergência em coordenação e com a participação de todos os envolvidos, incluindo administradores de instalações perigosas, funcionários e comunidades vizinhas; garantir que os sistemas de alarme de emergências e desastres estejam disponíveis para avisar à comunidade que venha a ser afetada; e facilitar e promover a disseminação de informação e troca de experiências associadas à prevenção, preparação e resposta às emergências e aos desastres químicos.

Nesse sentido, o trabalho tem por finalidade a criação de um banco de dados digital com as informações necessárias para se avaliar a vulnerabilidade populacional aos riscos tecnológicos existentes na cidade de Manaus-AM.

A partir da criação desse banco de dados, foi produzida uma série de cartogramas, que permitiu o cruzamento de informações para posteriores avaliações, cujo produto tornará mais fácil a visualização dos riscos, uma vez que eles estarão espacializados e georreferenciados, e servir como uma ferramenta didática, inclusive como subsídio para a criação de programas que visem ao cumprimento da agenda mundial Objetivos de Desenvolvimento Sustentável (ODS) da ONU, mais especificadamente do $11^{\circ}$ ODS, o qual traz entre suas metas tornar as cidades mais inclusivas, seguras, sustentáveis e resilientes a desastres ou a eventos incomuns.

Este tipo de trabalho é de fundamental importância no que diz respeito à elaboração e implantação de técnicas de planejamento urbano e ambiental para uma determinada área ou cidade; pois, se esse estudo for levado em consideração pelos órgãos municipais competentes (Secretarias de Planejamento Estratégico, Defesa Civil e Meio Ambiente) e despertar a atenção dos pesquisadores, 
muitos dos meios e esforços serão economizados, possibilitando uma melhor gestão urbana da cidade de Manaus-AM. Além de subsidiar os órgãos de planejamento municipal, a avaliação dos riscos tecnológicos pode servir de instrumento na construção da sua percepção por parte da comunidade, pois, conhecendo a que tipo de riscos está exposta, poderá conviver melhor com ele, conseguindo, assim, exercer sua cidadania e exigir seus direitos.

A literatura técnica, por seu turno, tem dado muita ênfase ao estudo da vulnerabilidade, considerando a necessidade de reduzi-la mediante a adoção de medidas de prevenção-mitigação. Na realidade, o que se procura nesses casos é a redução do risco. Por isso, muitas vezes, ela é confundida com o próprio risco (Rosa, 2008).

Li et al. (2010) exploram o conceito de vulnerabilidade sob o enfoque social, ao mapear a vulnerabilidade aos acidentes químicos do entorno de um parque industrial na cidade de Nanjing, na China. Já uma aplicação ambiental do conceito de vulnerabilidade pode ser encontrada no trabalho de Mendoza-Cantú et al. (2011), enquanto a característica intrínseca dentro de uma área que determina a extensão dos danos. No estudo, foram identificadas as áreas ambientalmente vulneráveis a vazamentos de oleodutos.

No tocante a uma aplicação do conceito de vulnerabilidade de cunho mais prático e integrador, é observada em Tixier et al. (2006), que se propõem a avaliar a vulnerabilidade no entorno de uma planta industrial. No estudo, os autores definem o conceito de vulnerabilidade como o grau de perda de um determinado elemento, ou conjunto de tais elementos resultantes da ocorrência de um fenômeno de uma dada magnitude. Para isso, identificam e quantificam possíveis alvos humanos (trabalhadores industriais, população local, estabelecimentos públicos, linhas de comunicação), ambientais (áreas cultiváveis, áreas naturais, corpos hídricos) e materiais (plantas industriais, infraestruturas, estruturas privadas e públicas).

Embora as inúmeras noções sobre vulnerabilidade, com amplos conceitos e designações, formem percepções confusas, ambíguas e até mesmo conflitantes, essas definições permitem compreender que a vulnerabilidade não é tanto um fenômeno externo e observável, mas uma comparação relativa entre os condicionantes ambientais, sociais, econômicos e políticos, e sua avaliação é uma das ferramentas potenciais para gerar sistemas de resposta preventiva (Rodrigues, 2008). Ou seja, a vulnerabilidade é vista como o outro lado da sustentabilidade, em que o aumento de uma implica na diminuição da outra. Assim, quanto mais cedo conhecermos a vulnerabilidade do ambiente ou de grupos organizados, mais cedo esses ambientes e grupos sociais podem receber os devidos cuidados, tornando-se sociedades mais sustentáveis que consigam lidar com certo grau de incerteza e insegurança (Hogan et al., 2010).

São numerosos os fatores que permitem estimar a vulnerabilidade de determinadas áreas. É preferível que eles sejam classificados segundo a sua importância e que a escala de trabalho seja selecionada com o devido cuidado, de acordo com a área e a confiabilidade dos dados disponíveis, objetivando extrair um valor de vulnerabilidade para cada unidade de área estabelecida.

Mapear as vulnerabilidades permite não só a visualização de determinados grupos populacionais e áreas vulneráveis a situações de riscos específicos, mas permite ainda a realização de uma análise que auxilie no esclarecimento dos processos que dão 
origem ou contribuem para tais vulnerabilidades. Esta análise, por sua vez, incentiva a criação de estratégias e políticas públicas capazes de atingir melhorias no enfrentamento do risco. A análise de um mapa de vulnerabilidades torna-se, então, elemento estratégico na contextualização e na formulação de táticas de prevenção do risco, assim como na possibilidade de levar a discussão a nível coletivo de forma mais efetiva (Luiz, 2013).

\section{Metodologia}

O estudo foi desenvolvido na área urbana da cidade de Manaus, situada no estado do Amazonas. A área da unidade territorial é de 11.401,09 $\mathrm{km}^{2}$, sendo que, de acordo com o último estudo do IBGE sobre redes urbanas (2007), a área urbana corresponde a $483,39 \mathrm{~km}^{2}$. O Plano Diretor Urbano e Ambiental do município divide a cidade em 18 setores urbanos, abrangendo oficialmente 63 bairros (a lista de bairros é fornecida no apêndice).

Manaus, por seu turno, é um dos maiores centros industriais do Brasil. As mais importantes indústrias da cidade atuam na área de transportes e comunicações, estando a maior parte das fábricas e indústrias beneficiadas pelos incentivos fiscais da Zona Franca de Manaus localizada no Distrito Industrial, na zona sul da cidade, e algumas destas, próximas à fonte de matérias-primas, como a extração de minerais e madeiras, com pequeno beneficiamento dos produtos. A energia proveniente do gás natural da região possibilita a algumas áreas o crescimento no setor industrial, visando à exportação.

Com a expansão urbana de Manaus nas últimas décadas, a população aumentou de forma acelerada e, por vezes, desordenada. Segundo dados do IBGE, Manaus possuía, em 1960, um total de 175.343 habitantes, população quase seis vezes menor do que a de 1991, ano em que Manaus possuía 1.010.544 habitantes. Já em 2010, ano em que foi realizada a última contagem, foram constatados 1.792 .881 habitantes na área urbana e 9.133 na área rural, totalizando 1.802.014 habitantes, quase dobrando a população em 19 anos.

$\mathrm{Na}$ atualidade, Manaus é ao menos três vezes mais rica do que há três décadas, representando mais da metade da economia do estado do Amazonas. De acordo com o IBGE, a cidade ocupava, em 2013, a sexta posição no ranking do PIB do país.

Assim, a opção pela área de estudo foi devida a essas características peculiares que a cidade apresenta: um rápido e intenso desenvolvimento e crescimento urbano, abrangendo um maior aporte de fontes geradoras de riscos tecnológicos.

Para a realização da pesquisa, foi necessário, inicialmente, definir quais os fatores classificados como de riscos tecnológicos ambientais. Para isso, foram levados em consideração os que mais representam ameaças para a população e para o meio ambiente, de acordo com os estudos já realizados e manuais de análise de riscos.

Os fatores de risco tecnológico apresentam características que, dependendo de como são gerenciadas, podem causar os acidentes tecnológicos, os quais devem ser objeto de conhecimento das comunidades, para que possam interpretar melhor os danos que eventualmente venham a ocasionar, se não forem devidamente controlados, administrados e gestionados.

Desse modo, os fatores identificados e caracterizados como ameaças que poderiam causar algum dano foram as termelétricas, indústrias que 
utilizam solventes e/ou gases (linhas de gás/GLP), áreas portuárias, áreas de disposição de resíduos (aterros, lixões, recicladores e incineradores), áreas aeroportuárias e depósito de combustíveis (postos de revenda de combustíveis e refinarias de petróleo).

O levantamento desses fatores de riscos tecnológicos ambientais foi realizado por meio de dados disponibilizados pelos órgãos locais (SEMMAS, IPAAM e IMPLURB), e também com dados disponíveis em meio digital pela ANEEL, CIGAS, Ministério dos transportes, portos e aviação civil, ANAC e ANP.

Agrupados todos esses elementos numa base cartográfica, foi possível observar os diferentes níveis de riscos tecnológicos, isto é, onde existe maior ou menor ocorrência de fatores de risco tecnológico. Dessa forma, foi possível apontar as áreas mais críticas. A avaliação foi feita por meio da ocorrência de fatores por bairro, representando os bairros com maior concentração de fatores uma maior ameaça, e os com menor concentração deles, consequentemente, uma ameaça menor - e, assim, sucessivamente. Os níveis de risco foram divididos em cinco classes de faixas de tamanho crescente, com exceção dos extremos, que tiveram amplitude diferenciada, por serem convenientes para representar valores na extremidade da tabela, resultando em: desprezível (de 1 a 3 ocorrências de fatores de riscos tecnológicos ambientais), baixo (de 4 a 6), moderado (de 7 a 10), sério (de 11 a 15) e crítico (mais de 15).

Uma vez que o tema da pesquisa se restringe à integração das informações geográficas da análise da vulnerabilidade, os cenários acidentais, bem como as mudanças possíveis a partir da ocorrência de um evento não desejável - como as discutidas no trabalho de Freitas et al. (2000), tendo como refe- rência casos de eventos passados e situações críticas presentes - não foram levados em consideração no estudo, limitando-se apenas aos dados espaciais de tais fatores de risco. Assim, para este trabalho, as áreas de risco tecnológico ambiental foram definidas como as zonas onde existe a "possibilidade de ocorrer um acidente".

Com a utilização dos dados populacionais do Censo Demográfico do IBGE, do Plano Diretor Urbano e Ambiental de Manaus e do auxílio do SIG, foram classificadas as áreas urbanas (bairros de residência), segundo sua densidade populacional bruta, em: baixíssima densidade (até 47,5 habitantes por hectare), baixa densidade ( $>47,5$ até 95,0 habitantes por hectare), média densidade ( $>95,0$ até 142,50 habitantes por hectare), alta densidade ( $>142,50$ até 190,0 habitantes por hectare) e altíssima densidade ( $>$ 190,0 até 237,50 habitantes por hectare).

Também com o auxílio do SIG, e com dados do Atlas do Desenvolvimento Humano do Brasil (2010), foi elaborado o Mapa de distribuição do Índice de Desenvolvimento Humano Municipal dimensão Renda, por bairro. A dimensão renda do IDHM considera a renda per capita da população, ou seja, a renda média mensal dos indivíduos residentes em determinado lugar (município, Unidade Federativa, região metropolitana ou UDH), expressa em reais de $1^{\circ}$ de agosto de 2010. Dessa forma, as classes de IDHM foram definidas como: altíssimo (de 0,921 a 1,0), alto (de 0,841 a 0,920$)$, médio (de $0,761$ a 0,840$)$, baixo (de 0,681 a 0,760$)$ e baixíssimo (de 0,601 a 0,680).

A ideia de inserir o condicionante do IDHM no estudo está ligada ao fato de que as condições financeiras também caracterizam o quanto aquela área pode ser mais ou menos afetada. Está também diretamente relacionada ao tipo e condições de 
moradia que os habitantes daquela área possuem e o quão resistentes podem ser frente aos riscos tecnológicos ambientais.

Assim, para fins metodológicos e analíticos, a vulnerabilidade populacional aos riscos tecnológicos foi avaliada por meio de uma análise multicritérios tendo em consideração três dimensões: a quantidade de habitantes expostos aos diferentes processos perigosos (densidade populacional), a resistência que esses habitantes possuem aos riscos, relacionada ao fator financeiro (IDHM), e os níveis de riscos tecnológicos ambientais de cada área (ocorrência de fatores de risco).

Com o cruzamento dos dados dos mapas produzidos, realizado com o auxílio do editor de planilhas Excel do pacote Microsoft Office e, por meio da combinação dos dados levantados, foram obtidas as informações capazes de avaliar o quanto a população está vulnerável aos diferentes níveis de riscos tecnológicos existentes na área estudada. As sínteses desses cruzamentos de informações podem ser observadas nas Figuras abaixo, esquematizadas em formato de matriz.

No primeiro cruzamento, foram utilizados os dados de IDHM e de densidade populacional, resultando no que foi chamado no trabalho de níveis de "fragilidade" (Figura 1). Dessa forma, os níveis de fragilidade dos bairros obtidos foram: extremamente frágil, muito frágil, frágil, pouco frágil e não frágil.

No segundo cruzamento, com o intuito de serem determinados os níveis de vulnerabilidade populacional, foram utilizados os dados resultantes do primeiro cruzamento (níveis de fragilidade) e os dados de níveis de risco tecnológico, conforme observado na Figura 2.

\begin{tabular}{|c|c|c|c|c|c|c|}
\hline & \multicolumn{5}{|c|}{ Densidade Populacional } \\
\hline & & Altissima & Alta & Média & Baixa & Baixissima \\
\hline \multirow{5}{*}{$\begin{array}{c}\text { Índice de } \\
\text { Desenvolvimento } \\
\text { Humano- } \\
\text { Dimensão Renda }\end{array}$} & Baixíssimo & $\begin{array}{c}\text { Extremamente } \\
\text { Frágil }\end{array}$ & $\begin{array}{l}\text { Extremamente } \\
\text { Frágil }\end{array}$ & $\begin{array}{c}\text { Extremamente } \\
\text { Frágil }\end{array}$ & $\begin{array}{l}\text { Muito } \\
\text { Frágil }\end{array}$ & Frágil \\
\hline & Baixo & $\begin{array}{l}\text { Extremamente } \\
\text { Frágil }\end{array}$ & $\begin{array}{c}\text { Extremamente } \\
\text { Frágil }\end{array}$ & $\begin{array}{l}\text { Muito } \\
\text { Frágil }\end{array}$ & Frágil & $\begin{array}{l}\text { Pouco } \\
\text { Frágil }\end{array}$ \\
\hline & Médio & $\begin{array}{l}\text { Extremamente } \\
\text { Frágil }\end{array}$ & $\begin{array}{l}\text { Muito } \\
\text { Frágil }\end{array}$ & Frágil & Frágil & $\begin{array}{l}\text { Pouco } \\
\text { Frágil }\end{array}$ \\
\hline & Alto & $\begin{array}{l}\text { Muito } \\
\text { Frágil }\end{array}$ & Frágil & Frágil & $\begin{array}{l}\text { Pouco } \\
\text { Frágil }\end{array}$ & $\begin{array}{l}\text { Não } \\
\text { Frágil }\end{array}$ \\
\hline & Altissimo & Frágil & $\begin{array}{l}\text { Pouco } \\
\text { Frágil }\end{array}$ & $\begin{array}{l}\text { Pouco } \\
\text { Frágil }\end{array}$ & $\begin{array}{c}\text { Não } \\
\text { Frágil }\end{array}$ & $\begin{array}{l}\text { Não } \\
\text { Frágil }\end{array}$ \\
\hline
\end{tabular}

FIGURA 1 - Matriz utilizada para o cruzamento de dados com vistas à classificação dos níveis de fragilidades do bairro. 


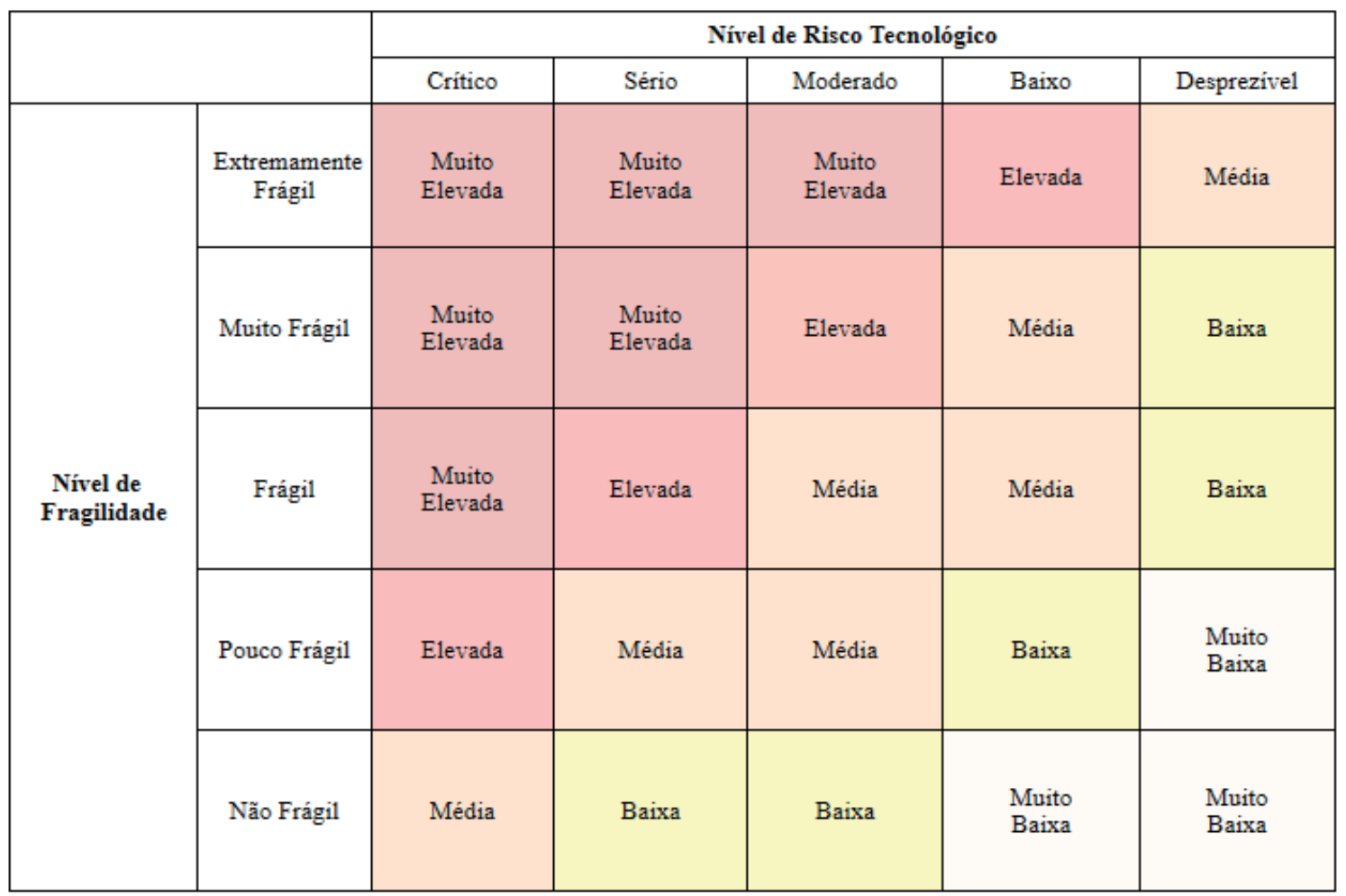

FIGURA 2 - Matriz utilizada para o cruzamento dos dados objetivando a obtenção dos níveis de vulnerabilidade populacional definidos para o estudo.

A partir da combinação das variáveis, foram construídas cinco categorias de vulnerabilidade populacional, ao nível de bairro:

a) Muito baixa vulnerabilidade: combinação de áreas de desprezível risco com áreas pouco ou não frágeis; e combinação de áreas de baixo risco com áreas não frágeis.

b) Baixa vulnerabilidade: combinação de áreas de desprezível risco com áreas muito frágeis ou frágeis; combinação de áreas de risco baixo com áreas pouco frágeis; e combinação de áreas não frágeis com áreas de sério ou moderado risco. c) Média vulnerabilidade: combinação de áreas de desprezível risco com áreas extremamente frágeis; combinação de áreas de baixo risco com áreas muito frágeis ou frágeis; combinação de áreas de moderado risco com áreas pouco frágeis ou frágeis; combinação de áreas de sério risco com áreas pouco frágeis; e combinação de áreas de crítico risco com áreas não frágeis.

d) Elevada vulnerabilidade: combinação de áreas de baixo risco com áreas extremamente frágeis; combinação de áreas de moderado risco com áreas muito frágeis; combinação de áreas de sério 
risco com áreas frágeis; e combinação de áreas de crítico risco com áreas pouco frágeis.

e) Muito elevada vulnerabilidade: combinação de áreas de moderado risco com áreas extremamente frágeis; combinação de áreas de sério risco com áreas extremamente ou muito frágeis; e combinação de áreas de crítico risco com áreas extremamente frágeis ou muito frágeis ou frágeis.

Este trabalho, contudo, não teve a pretensão de compreender todas as dimensões e aspectos citados pelos autores reconhecidos na área. A seleção dos fatores e variáveis decorreu dos dados disponíveis em bases de dados do IBGE, do Atlas Brasil e de algumas informações possíveis de serem coletadas em campo e disponibilizadas pelos órgãos de regulação e fiscalização.

De maneira geral, para o desenvolvimento de todas as etapas, foi realizado o levantamento bibliográfico em revistas e periódicos científicos específicos da área, livros, dissertações, manuais técnicos e documentos relacionados ao tema da pesquisa. Com a utilização da Internet, rede mundial de computadores, foi possível localizar os principais centros de pesquisas e as universidades de diversos países que têm trabalhado na área e, assim, ter acesso aos trabalhos e livros publicados no exterior.

Para a realização do levantamento e a elaboração dos produtos cartográficos, bem como a geração de banco de dados, análise espacial dos dados geográficos, criação de layouts e plotagens dos mapas, foram utilizadas as informações disponíveis no banco de dados do IBGE, Atlas Brasil e o software QGIS, um SIG livre licenciado sob a "GNU - General Public License".

O estudo ainda contou com trabalho de campo, por meio do qual foram realizadas visitas às fontes dos fatores de riscos tecnológicos ambientais, a fim de certificar a existência dos já citados riscos. A realização dessa etapa também teve auxílio do software Google Earth, o qual possibilita a análise visual de imagens de satélite.

A edição dos textos e a tabulação dos dados foram executadas por meio do editor de textos Word e do editor de planilhas Excel do pacote Microsoft Office.

As avaliações ambientais podem ser mais bem desenvolvidas e mesmo quantificadas, quando se faz uso dos mapas temáticos. Entretanto, a leitura, interpretação e cruzamento da grande quantidade de informações disponíveis nesses mapas só se tornam efetivas e confiáveis quando se dispõe de ferramentas poderosas para armazenamento, manipulação e interpretação desses dados. Isso tem sido satisfatoriamente feito com o uso do geoprocessamento e dos sistemas de informação geográficas. As técnicas de mapeamento por meio do uso de SIGs adquirem grande importância na medida em que, por meio destes, é possível realizar a aquisição, armazenamento, manipulação, análise e apresentação de dados georreferenciados, o que torna mais práticas análises complexas que exijam a integração de dados de fontes variadas.

A utilização de SIGs em estudos de riscos e vulnerabilidades tem ganhado cada vez mais espaço, como pode ser observado no trabalho de Kumpulainen (2006), no qual foi elaborado o mapeamento da vulnerabilidade de todo o espaço europeu abrangido pela ESPON, identificando cinco classes de vulnerabilidades, através da reunião e análise de dados de renda per capita regional e nacional, densidade populacional e proporção de áreas naturais fragmentadas. Corroborando essa ideia, Cartier et al. (2009) mapeou e analisou, por intermédio de um SIG, cinco áreas vulneráveis con- 
cêntricas a um distrito industrial na cidade de Rio de Janeiro. Utilizando-se de indicadores socioeconômicos, demográficos e de infraestrutura, chegou à conclusão de que existe forte correlação entre os grupos socialmente mais vulneráveis e os riscos ambientais, tendo por referência a proximidade das indústrias na região.

Nesse mesmo sentido, Yang \& Ma (2010) elaboraram, com a utilização da função clusterização do SPSS e SIG, o mapa de zoneamento dos riscos de Xangai, China, apontando as áreas com maiores e menores níveis de risco tecnológico.

Com o objetivo de desenvolver uma metodologia para descrever os riscos decorrentes do transporte de produtos perigosos na província de Valladolid, na Espanha, Martínez-Alegría et al. (2003) elaboraram, em ambiente SIG, o mapeamento das vulnerabilidades ambientais e populacionais da região, utilizando dados demográficos e de infraestruturas.

Dentre os autores que têm se dedicado aos estudos de vulnerabilidade no território brasileiro, cita-se Alves (2006), que analisou a vulnerabilidade da metrópole paulistana, sendo, no estudo, a categoria de vulnerabilidade socioambiental estudada por meio de indicadores sociais e ambientais. Em sua metodologia de trabalho, propôs uma tipologia simples, em que os setores censitários do município de São Paulo são classificados em quatro categorias de vulnerabilidade, resultantes da combinação das duas dimensões: risco ambiental (proximidade dos cursos d'água) e degradação ambiental (baixa cobertura de esgoto).

Outro exemplo de pesquisa brasileira é a de Carmo \& Rocha (2005), que visou a espacializar os diferentes níveis de risco tecnológico em uma área piloto da cidade de Juiz de Fora - MG, avaliando as vulnerabilidades da população a este risco, a fim de embasar técnicas de planejamento urbano e ambiental.

Também nessa escala de trabalho, Luiz (2013) realizou o mapeamento da vulnerabilidade da área de entorno do distrito industrial do município de Paulínia, e a identificação dos alvos mais sensíveis à ocorrência de acidentes. No trabalho, ainda foi avaliada a sua aplicação para o contexto brasileiro e sua utilização como instrumento de gestão de uso do solo no entorno de plantas industriais.

De maneira geral, os resultados dos estudos citados salientam a importância desse tipo de análise para a adequação das políticas públicas e para a organização territorial, com vistas a apontar a maior ou menor resistência e resiliência dos indivíduos ou das comunidades aos riscos tecnológicos.

O uso dos SIGs, nos estudos acadêmicos, instituições de governos e empresas privadas, tem aumentado a cada dia. Porém, o seu universo de aplicação ainda é vasto, se for levado em conta o potencial desses sistemas e a escassez de informações adequadas para a tomada de decisões sobre questões complexas, como é o caso da identificação de áreas vulneráveis e os riscos envolvidos.

Os resultados são apresentados em formato de mapas, em uma escala espacial por bairros, na cidade de Manaus. Os fatores de riscos tecnológicos ambientais delimitados para o estudo que são as termelétricas, as indústrias que utilizam solventes e/ou gases (linhas de gás/GLP), áreas portuárias, áreas de disposição de resíduos (aterros, lixões, recicladores e incineradores), áreas aeroportuárias e os depósitos de combustíveis (postos de revenda de combustíveis e refinarias de petróleo). 


\section{Análise e discussão dos resultados}

\subsection{Nivel de risco tecnológico ambiental}

Sobrepostos os fatores de risco tecnológico em uma base cartográfica, foi possível analisar os diferentes níveis de risco tecnológico existentes na cidade de Manaus, lugar onde existe maior ou menor ocorrência desses fatores.

O mapa dos riscos acumulados foi denominado de Mapa dos fatores de risco tecnológico ambiental na área urbana de Manaus (Figura 3). Quando analisado espacialmente, é possível constatar que todas as áreas da cidade apresentam algum tipo de risco tecnológico, com exceção dos bairros: Armando Mendes, Glória, Monte das Oliveiras, Novo Israel, Santa Luzia, São Lázaro e Vila da Prata.

Ainda analisando o mapa, pode-se considerar que a presença dos fatores de risco se concentra na área sul da cidade, enfatizando a localização dos bairros mais antigos da capital amazonense, abrangendo o Centro Histórico de Manaus, bem como áreas comerciais e residenciais.

Como esperado, o Distrito Industrial I apresentou o maior número de ocorrências de fatores de riscos tecnológicos ambientais. Isto se justifica devido às características peculiares da região, que foi planejada para ser uma área de aporte de indústrias.

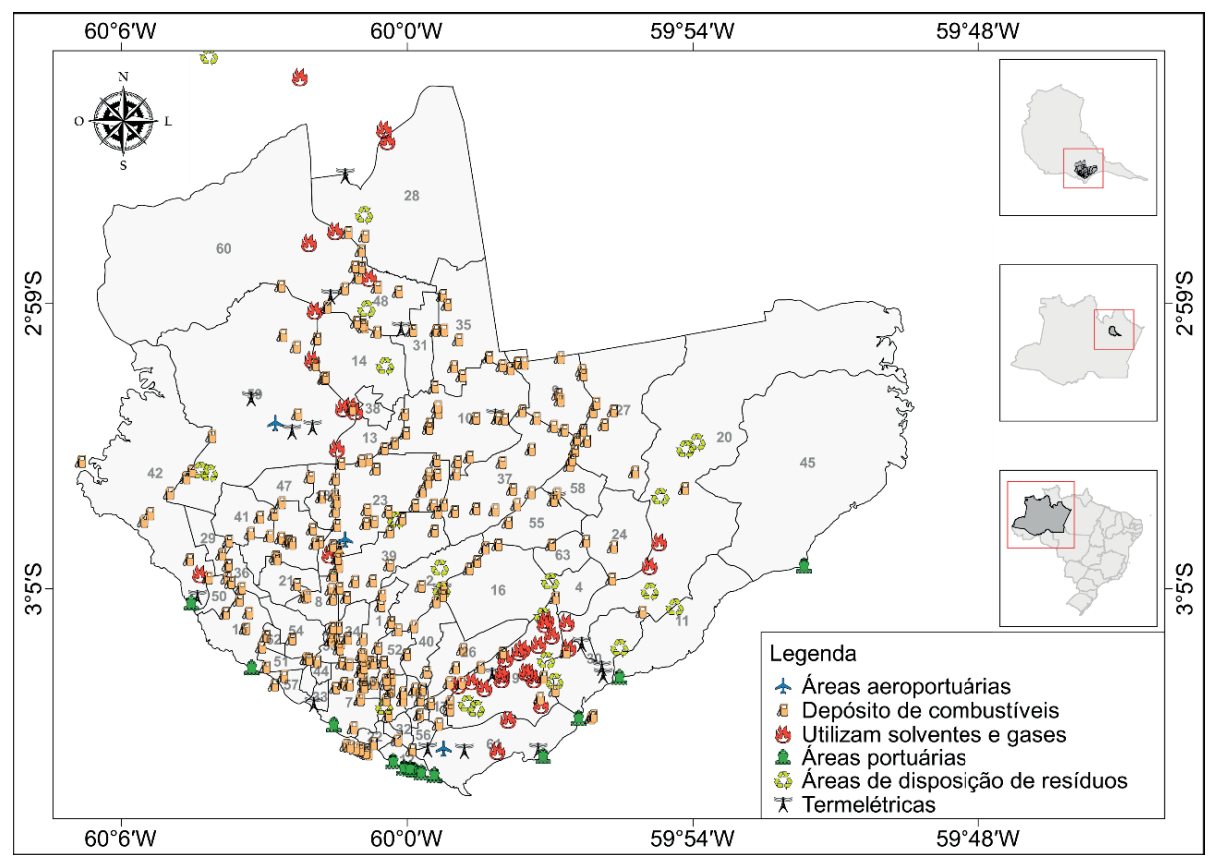

FIGURA 3 - Mapa com a plotagem dos fatores de risco tecnológico ambiental delimitados para o estudo. Os números representam os bairros conforme a lista no apêndice.

FONTE DE DADOS: ANEEL (2017); ANP (2017); CIGÁS (2016); IBGE (2010); ANAC (2017); IPAAM (2017); Manaus (2014); SEMMAS (2017); SEP/PR (2017). Sistemas de Coordenadas Geográficas. Datum: SIRGAS 2000. Escala: 1:50.000. 
O bairro de Flores, por ser um bairro de grande fluxo de automóveis e de transição entre as zonas norte e sul da cidade, apresentou um número elevado de ocorrências de fatores de risco em decorrência da existência de muitos postos de combustíveis na região. Outro bairro que também teve destaque, devido à elevada ocorrência de fatores de risco, foi o Tarumã. Tal fato pode ser explicado dada a sua localização, mais periférica, podendo abrigar empreendimentos de grande porte, como o aeroporto, e também devido à sua grande extensão territorial ( $4^{\mathrm{a}}$ maior da cidade).
Por meio do Mapa de níveis de risco tecnológico ambiental na área urbana de Manaus (Figura 4), analisou-se que grande parte da área estudada está ocupada por desprezível ou baixo nível de risco tecnológico. Entretanto, os níveis moderado, sério e crítico representam uma parcela significativa da área de estudo. Somando essas categorias, tem-se um total de 315,82 $\mathrm{km}^{2}(65,33 \%$ da área total).

Ao contrário da concentração dos fatores de risco que se deu ao sul da cidade, os bairros que apresentaram o maior número de ocorrências de fatores de risco estão localizados nas suas zonas

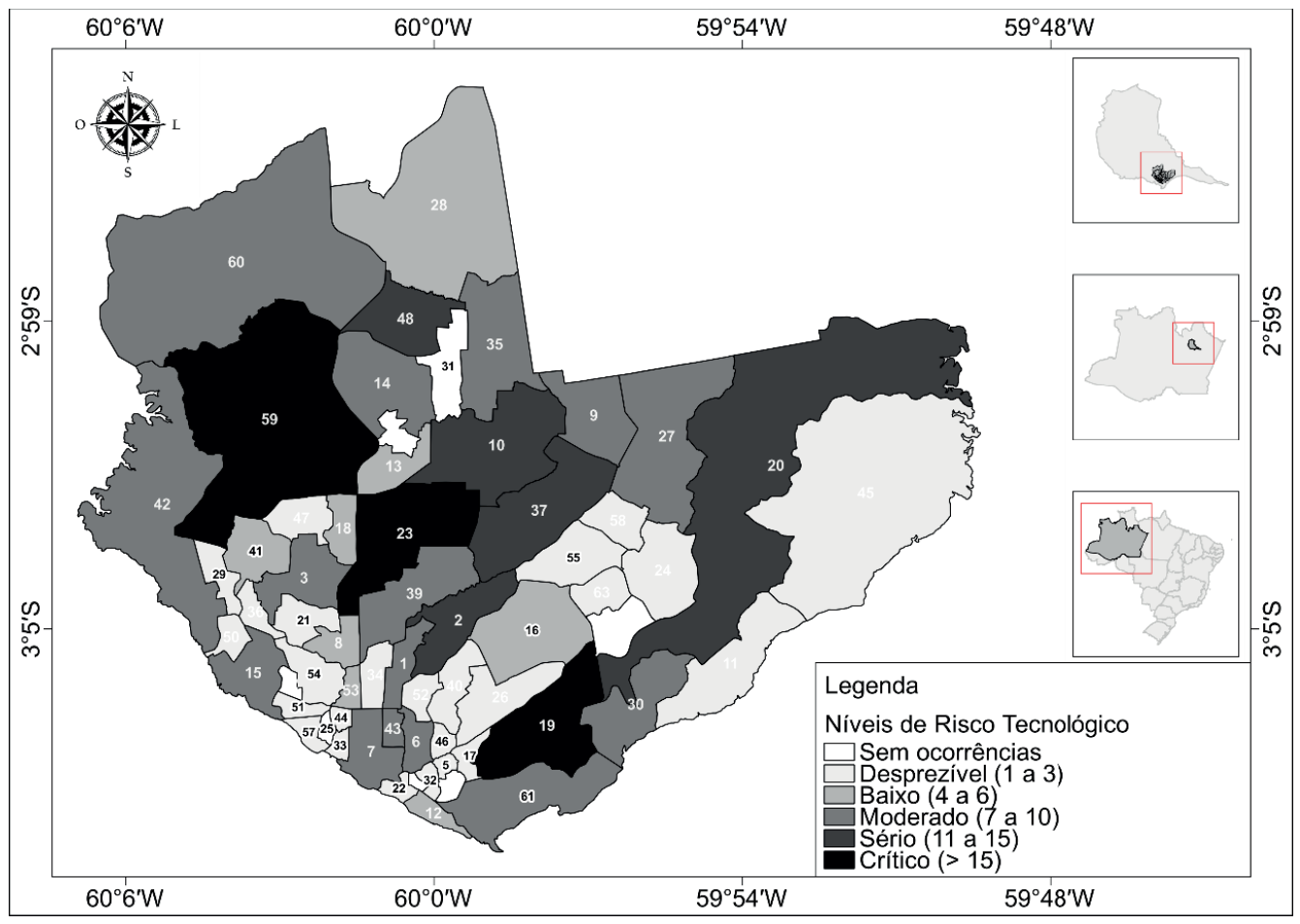

FIGURA 4 - Mapa dos níveis de risco tecnológico ambiental dos bairros da área urbana de Manaus. Os números representam os bairros conforme a lista no apêndice.

FONTE DE DADOS: ANEEL (2017); ANP (2017); CIGÁS (2016); IBGE (2010); ANAC (2017); IPAAM (2017); Manaus (2014); SEMMAS (2017); SEP/PR (2017). Sistemas de Coordenadas Geográficas. Datum: SIRGAS 2000. Escala: 1:50.000. 
norte, sendo eles Cidade Nova, Distrito Industrial II Flores, Novo Aleixo, Santa Etelvina e Tarumã.

\subsection{Mapeamento da vulnerabilidade populacional aos riscos tecnológicos ambientais}

A partir da análise dos dados de níveis de risco, densidade populacional e Índice de Desenvolvimento Humano, obteve-se um mapa no qual foram avaliados os diferentes níveis de vulnerabilidade aos riscos tecnológicos em que se encontra a população existente na área estudada.
Primeiramente, foram cruzados os dados de densidade populacional e IDH, resultando no que foi chamado no trabalho de níveis de "fragilidade". O resultado espacializado desse cruzamento pode ser observado na Figura 5 - Mapa de níveis de fragilidade dos bairros da área urbana de Manaus.

Com o cruzamento dos dados dos níveis de fragilidade e de níveis de risco tecnológico, foram encontrados os níveis de vulnerabilidade populacional por bairro, expressos no Mapa de vulnerabilidade populacional aos riscos tecnológicos ambientais na área urbana de Manaus (Figura 6). Observando este mapa, pode-se constatar que as áreas mais vul-

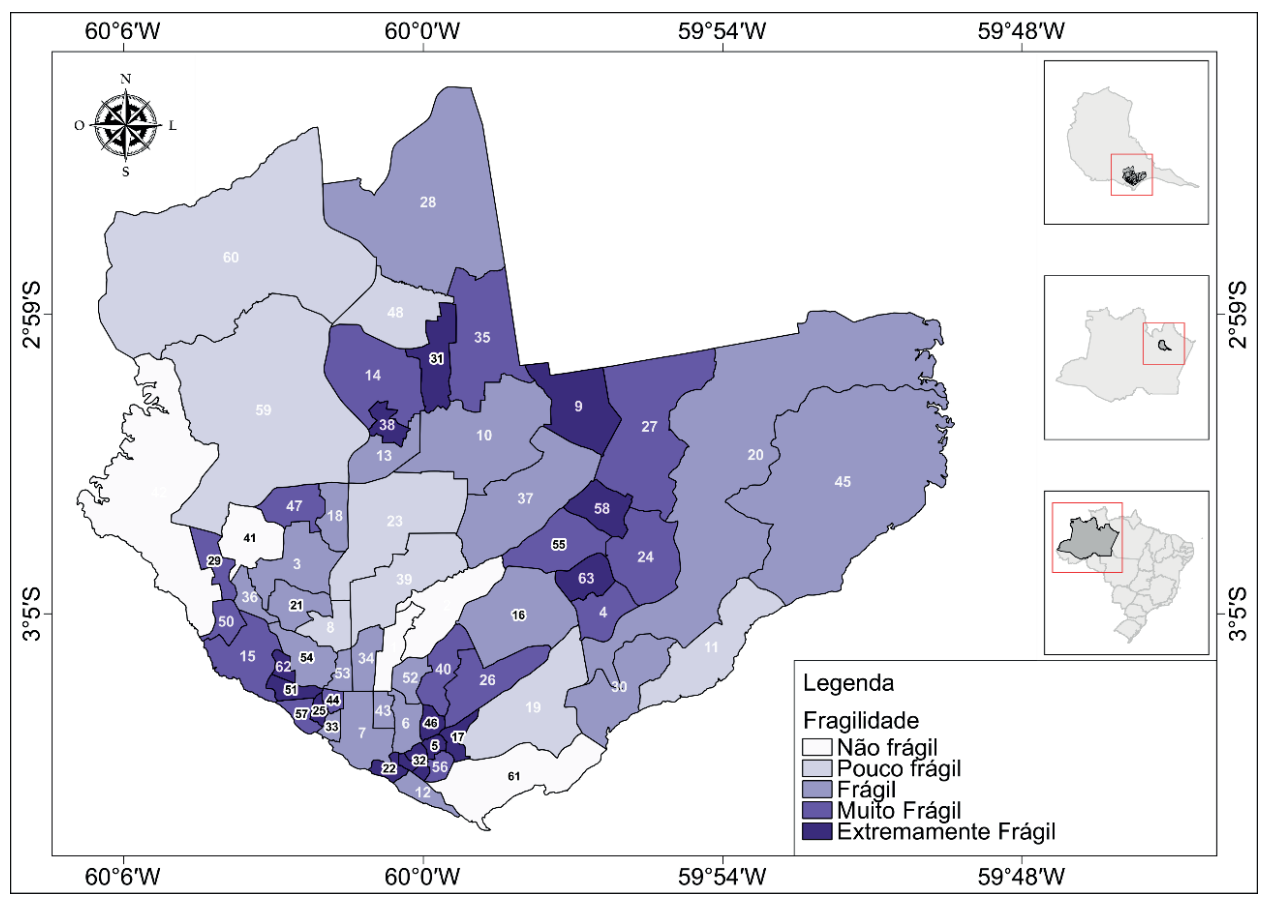

FIGURA 5 - Mapa dos níveis de fragilidade dos bairros da área urbana de Manaus. Destacam-se os bairros mais frágeis aos extremos nordeste e sudoeste. Os números representam os bairros conforme a lista no apêndice.

FONTE DE DADOS: ATLAS BRASL (2010); IBGE (2010); Manaus (2014). Sistemas de Coordenadas Geográficas. Datum: SIRGAS 2000. Escala: 1:50.000. 
neráveis estão localizadas nas zonas norte e leste da cidade, áreas de grande concentração populacional, baixo IDH e com a presença de fatores de riscos tecnológicos.

Com os dados obtidos, nota-se ainda que as classes de muito baixa e baixa vulnerabilidade representam uma grande área do mapa. Contudo, a preocupação que se deve ter é com as categorias de média e, principalmente, elevada e muito elevada vulnerabilidade. Essas duas últimas categorias somam $39,25 \%$ da área urbana da cidade, totalizando $189,73 \mathrm{~km}^{2}$.

A espacialização dos resultados pode comprovar que a vulnerabilidade desses bairros está intimamente relacionada com a alta densidade populacional, o baixo Índice de Desenvolvimento Humano e o elevado nível de risco tecnológico.

De modo geral, os resultados mostram que as áreas (bairros) com vulnerabilidade muito elevada possuem condições socioeconômicas piores, além de maior concentração populacional do que aquelas com baixa e média vulnerabilidade. Algumas possíveis explicações para essa elevada concentração de problemas e riscos sociais e tecnológicos nas áreas de elevada vulnerabilidade são discutidas a seguir.

A primeira delas está ligada ao fato de que as áreas de mais risco e mais afastadas são as únicas acessíveis à população de menor renda, por serem muito desvalorizadas no mercado imobiliário,

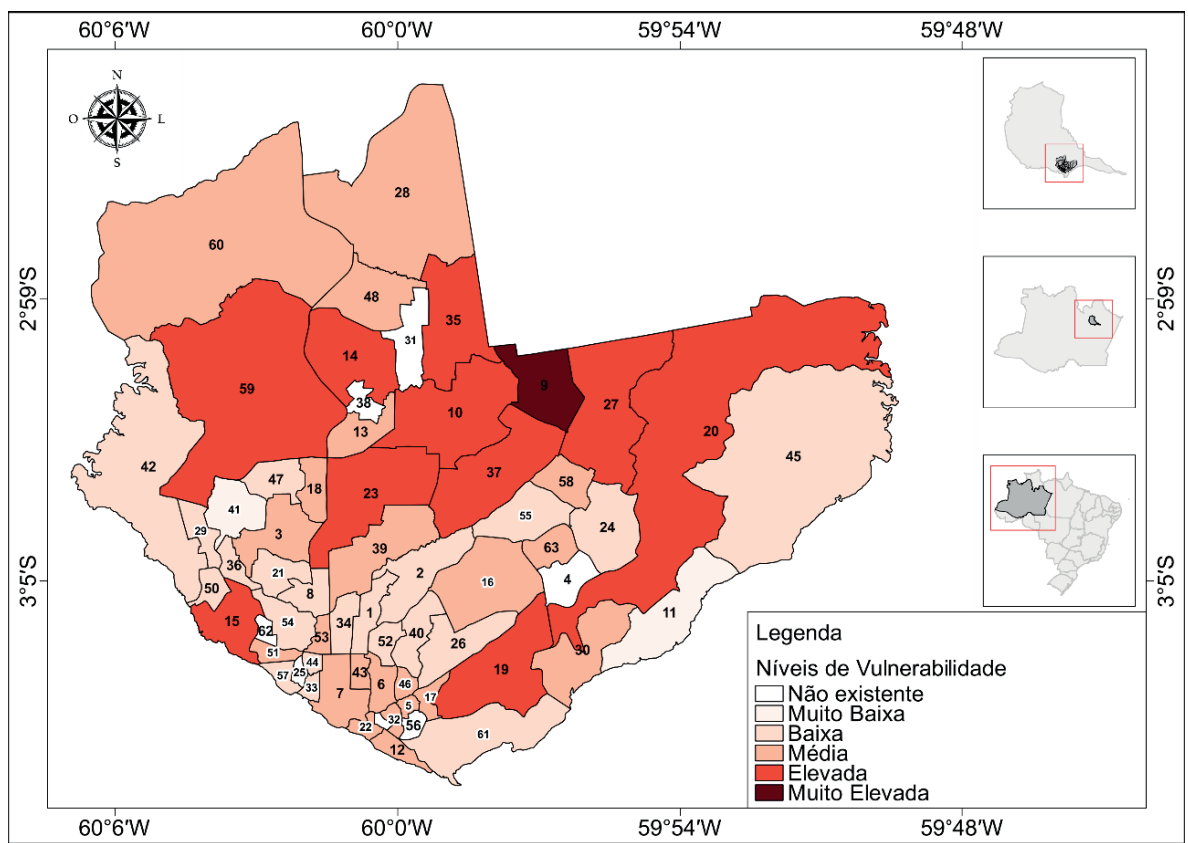

FIGURA 6 - Mapa da vulnerabilidade populacional aos riscos tecnológicos ambientais dos bairros da área urbana de Manaus. Os números representam os bairros conforme a lista no apêndice.

FONTE DE DADOS: ANEEL (2017); ANP (2017); ATLAS BRASIL (2010); CIGÁS (2016); IBGE (2010); ANAC (2017); IPAAM (2017); Manaus (2014); SEMMAS (2017); SEP/PR (2017). Sistemas de Coordenadas Geográficas. Datum: SIRGAS 2000. Escala: 1:50.000. 
devido às características de risco e falta de infraestrutura urbana.

Outra explicação é que essas zonas de grande concentração populacional e baixo Índice de Desenvolvimento Humano, na maioria das vezes, são áreas (públicas ou privadas) invadidas, em geral por assentamentos precários, que se configuram como áreas de "invasão".

Assim, a maioria das áreas de níveis elevados de vulnerabilidade populacional do perímetro urbano da cidade de Manaus corresponde a áreas de condições socioeconômicas precárias, de significativa concentração populacional e de fatores de risco tecnológico. Portanto, acredita-se que o planejamento e a formulação de políticas públicas para redução da vulnerabilidade populacional aos riscos tecnológicos devam estar focados, principalmente, nas políticas de urbanização. Devido ao fato de que o risco se constrói através de múltiplos processos relacionados com o desenvolvimento territorial, setorial, ambiental e social, a gestão deve ser considerada um componente íntimo dos processos de planejamento nesses ambientes, e não uma problemática à parte.

Cabe ainda recordar que uma das mais importantes vulnerabilidades da população brasileira é o baixíssimo senso de percepção de riscos e que, em consequência dessa vulnerabilidade, ocorrem comportamentos irresponsáveis, que resultam justamente na ocupação de áreas já superpovoadas e próximas às fontes geradoras de riscos (Brasil, 2003).

Com os resultados obtidos no mapeamento das vulnerabilidades, é plausível salientar a importância do planejamento territorial como instrumento legal, capaz de mitigar as consequências que os perigos relacionados aos fatores de risco tecnológico pos- sam causar. Ainda que algumas características da vulnerabilidade do entorno sejam levadas em conta, o uso do solo é o fator primordial em questões que envolvam planejamento territorial e acidentes tecnológicos (Cozzani et al., 2006).

Há uma preocupação, justificada, com os “acidentes tecnológicos ampliados", às vezes chamados de acidentes "maiores", especialmente quanto à proteção de vidas humanas. Esses eventos não desejáveis ocorrem, em sua grande maioria, devido a uma decisão inicial de planejamento territorial que permitiu a alocação de uma atividade perigosa em um lugar inapropriado, ou que não foi capaz de controlar os diversos usos do entorno, especialmente o residencial (Smith \& Petley, 2009).

\section{Considerações finais}

No presente trabalho, procurou-se operacionalizar a categoria vulnerabilidade populacional por meio da construção de indicadores, na escala da divisão administrativa da área urbana de Manaus (bairros), utilizando métodos e técnicas de geoprocessamento. Assim, foi utilizada uma metodologia para construir um indicador de vulnerabilidade populacional para estas áreas, formado pela combinação de variáveis de densidade populacional, Índice de Desenvolvimento Humano - Dimensão Renda e de risco tecnológico ambiental.

As diferentes visões sobre vulnerabilidade expostas no trabalho refletem a complexidade do tema, que possui diversas perspectivas analíticas, ligadas, muitas vezes, a ramos distintos de conhecimentos ou a filiações teóricas igualmente diferenciadas, o que, sem dúvida dificulta a operacionalização e mensuração do problema. Dessa forma, mesmo que 
exista um componente de subjetividade na conceituação teórica da vulnerabilidade, outros elementos que cercam o tema podem ser mensurados, e é por meio da busca de indicadores mensuráveis que a metodologia foi trabalhada.

Os resultados do trabalho, no que lhes concerne, expuseram que as áreas com elevada vulnerabilidade populacional apresentam condições socioeconômicas significativamente piores, além de maior concentração populacional, do que aquelas com menor grau de vulnerabilidade, o que revela a existência de áreas críticas, nas quais ocorre uma forte concentração de problemas de riscos sociais e tecnológicos ambientais. Dessa forma, são criadas situações em que, por conta de comportamentos irresponsáveis, os grupos sociais com maiores níveis de pobreza e privação social (e, portanto, com menor capacidade de reação às situações de risco) vão residir nas áreas com significativa exposição aos riscos tecnológicos e de alta concentração populacional, configurando-se cenários de elevada vulnerabilidade populacional aos riscos tecnológicos ambientais.

Essa sobreposição ou cumulatividade de riscos e problemas sociais torna-se um desafio para as políticas públicas, que, na maioria das vezes, são segregadas em setores de intervenção. Nesse sentido, este trabalho pode trazer subsídios relevantes para o planejamento de políticas públicas, ao identificar e caracterizar as áreas críticas de alta vulnerabilidade e de alta concentração de fatores de risco tecnológico, as quais poderiam ser alvo de esforços direcionados, visando à redução da vulnerabilidade. A chave para o controle de novos fatores de risco em novos assentamentos, zonas de desenvolvimento setorial, infraestrutura urbana, etc., é a normatização e implantação de controles sobre o uso do solo: o planejamento territorial. Adicionalmente, é imprescindível que se promovam processos através dos quais os tomadores de decisão dimensionem seus novos projetos de desenvolvimento, considerando os riscos e a sua redução.

Diante dos resultados obtidos com esta pesquisa, pode-se concluir que eles próprios servem de base à elaboração das sugestões que se seguem, voltadas para mitigar/controlar os riscos tecnológicos ambientais detectados na área onde foi realizado o estudo, e orientar o planejamento urbano futuro de Manaus, bem como servir de alerta para outros centros urbanos brasileiros. Em resumo, as implicações da pesquisa visam a possíveis aplicações em ações de gerenciamento territorial.

Concomitantemente com o planejamento territorial, que busca modificar as condições que agravam situações de vulnerabilidade, devem existir os programas de respostas às emergências ambientais, como é o caso do programa APELL, no qual, em sua edição mais recente (APELL, 2015): "Manual do APELL (Alerta e Preparação de Comunidades para Emergências Locais): Um processo para melhorar a conscientização e preparação da comunidade para os riscos tecnológicos e as emergências ambientais", faz-se uma contribuição importante para a redução do risco de desastres, por meio da prestação de orientação reforçada para três principais grupos de interessados (indústria, autoridades públicas e líderes comunitários) a se envolverem num processo participativo em reposta a esse desafio.

Entretanto, em Manaus, como as emergências, atendidas pela Defesa Civil, são mais voltadas para os riscos naturais, quais sejam deslizamentos e inundações, por exemplo, ainda não são trabalhados programas de respostas às emergências ambientais 
quanto aos riscos tecnológicos. Assim, talvez seja o momento oportuno de ser criado um departamento especializado em riscos tecnológicos, como é o caso da CETESB em São Paulo, que possui um Setor de Riscos Tecnológicos com o objetivo de diagnosticar, avaliar e reduzir o risco imposto ao meio ambiente e ao homem, por meio de medidas de mitigação e de gerenciamento. Por fim, essa possibilidade deve ser levada em consideração, uma vez que Manaus é uma região com grande potencial de crescimento, que no decorrer dos anos aportará cada vez mais empreendimentos classificados como fatores de riscos tecnológicos em seu território.

\section{Referências}

Alves, H. P. da F. Vulnerabilidade socioambiental na metrópole paulistana: uma análise sociodemográfica das situações de sobreposição espacial de problemas e riscos sociais e ambientais. Revista Brasileira de Estudos de População, 23(1), 43-59, 2006. Disponível em: <https://www.rebep. org.br/revista/article/view/228/pdf_214>

ANAC - Agência Nacional de Aviação Civil. Disponível em: <http://www.anac.gov.br/assuntos/setor-regulado>. Acesso em abril de 2017.

ANEEL - Agência Nacional de Energia Elétrica. Disponível em: < http://www.aneel.gov.br/dados/geracao $>$. Acesso em abril de 2017.

ANP - Agência Nacional do Petróleo, Gás Natural e Biocombustíveis. Disponível em: <https://postos.anp.gov.br/ consulta.asp $>$. Acesso em abril de 2017.

APELL - Alerta e Preparação de Comunidades para Emergências Locais. Manual do APELL: Um processo para melhorar a conscientização e preparação da comunidade para os riscos tecnológicos e as emergências ambientais. São Paulo: Programa das Nações Unidas para o Meio Ambiente (United Nation Environmental Proteccion - Unep), 2015.

Atlas do desenvolvimento humano no brasil. Rio de Janeiro,
PNUD, IPEA, Fundação Pinheiro, 2010. Disponível em: $<\mathrm{http}$ ://atlasbrasil.org.br>. Acesso em maio de 2017.

Brasil. Decreto-lei $n .^{\circ}$ 288, de 28 de fevereiro de 1967. Altera as disposições da Lei número 3.173 de 6 de junho de 1957 e regula a Zona Franca de Manaus. Brasília: DOU de 02/02/1967.

Brasil. Ministério da Integração Nacional. Manual de desastres humanos: desastres humanos de natureza tecnológica - v. 2. - I parte / Ministério da Integração Nacional. Secretaria Nacional de Defesa Civil. Brasília: MI, 2003. Disponível em: <http://www.ceped.ufsc.br/wp-content/ uploads/2014/07/destecnologicos.pdf $>$. Acesso em junho de 2017.

Brasil. Ministério do Meio Ambiente. Apostila do curso sobre estudo de análise riscos e programa de gerenciamento de riscos, 2006.

Brilhante, O. M.; Caldas, L. Q. de A. (Coords.). Gestão e avaliação de risco em saúde ambiental. Rio de Janeiro: Fiocruz, 1999.

Carmo, L. F. Z.; Rocha, G. C. Vulnerabilidade populacional a desastres tecnológicos na área urbana de Juiz de Fora-MG. Revista do Departamento de Geociências, 14(1), 2005. Disponível em: <http://www.uel.br/revistas/geografia/V14N1/ Artigo03.pdf $>$

Cartier, R.; Barcellos, C.; Hübner, C.; Porto, M. F. Vulnerabilidade social e risco ambiental: uma abordagem metodológica para avaliação ambiental. Cadernos de Saúde Pública, 25(12), 2695-2704, 2009. Disponível em: <http:// www.scielo.br/pdf/csp/v25n12/16>

CASTRO, S. M. Estratégias, politicas e práticas para reduzir o risco de perigos naturais e a vulnerabilidade. Disaster Preparedness Management. San Jose, Costa Rica: 2001.

CIGÁS - Companhia de Gás do Amazonas. Disponível em: $<$ http://www.cigas-am.com.br>. Acesso em abril de 2017.

Covello, V. T. E.; Mumpower, J. Risk analysis and risk management: an historical perspective. Risk Analysis. Londres, Butterworths, p. 103-120, 1985. doi: 0.1111/j.15396924.1985.tb00159.x

Cozzani, V.; Bandini, R.; Basta, C.; Christou, M. D. Application of land-use planning criteria for the control 
of major accident hazards: A case-study. Journal of Hazardous Materials, A136, 170-180, 2006. doi: 10.1016/j. jhazmat.2005.12.031

Dagnino, R. de S.; Capri Junior, S. Risco ambiental: conceitos e aplicações. Climatologia e estudos da Paisagem, 2(2), 50-86, 2007. Disponível em: <http://www.periodicos.rc.biblioteca.unesp.br/index.php/climatologia/article/ view/1026/958>

Egler, C. Risco ambiental como critério de gestão do território: uma aplicação à zona costeira brasileira. Revista Território, 1(1), 31-40, 1996. Disponível em: <http://www. revistaterritorio.com.br/pdf/01_4_egler.pdf $>$

Fernandes, B. de J.; Rocha, G. C. Educação sobre riscos ambientais e o Programa "Defesa Civil nas Escolas": uma proposta metodológica interdisciplinar. Virtú, Juiz de Fora, 5. ed., jan./jun., 2007. Disponível em: <http://www.ufjf.br/ virtu/files/2010/05/5a-4.pdf>

Freitas, C. M.; Porto, M. F. S.; Machado, J. M. H. (Orgs.). Acidentes industriais ampliados: desafios e perspectivas para o controle a prevenção [online]. Rio de Janeiro: Editora FIOCRUZ, 2000. doi: 10.747/9788575415085

Hogan, D, J.; Marandola Jr, E.; Ojima, R. População e ambiente: desafios à sustentabilidade. São Paulo: Blucher, 2010.

IBGE - Instituto Brasileiro de Geografia e Estatística. Censo Demográfico 1872, 1890, 1900, 1920, 1940, 1950, 1960, 1970, 1980, 1991, 2000 e 2010. Disponível em: $<$ http://www.censo2010.ibge.gov.br/sinopse/index.php?dados $=6 \& u f=00>$. Acesso em novembro de 2016.

IBGE - Instituto Brasileiro de Geografia e Estatística. Regiões de Influência das Cidades - 2007. Disponível em: $<$ http://www.ibge.gov.br/home/geociencias/geografia/regic. shtm?c=7>. Acesso em novembro de 2016.

IPAAM - Instituto de Proteção Ambiental do Amazonas. Disponível em: <http://www.licenciamentoambiental.am. gov.br>. Acesso em abril de 2017.

Kumpulainen, S. Vulnerability concepts in hazard and risk assessment. In: Schmidt-Thome, P. (Ed.). Natural and technological hazards and risks affecting the spatial development of European regions. Geological Survey of
Finland. Special Paper 42, p. 65-75, 2006.

Lavell, A. Desastres y desarrollo: hacia un entendimiento de las formas de construcción social de un desastre: el caso del huracán Mitch en Centroamérica. In: Garita, N.; Nowalski, J. (Orgs.). Del Desastre al Desarrollo Sostenible: El Caso de Mitch en Centroamerica. San José: BID y CIDHS, p. 1-28, 2000. Disponível em: <http://www.desenredando. org/public/articulos/2000/dyd/DyD2000_mar-1-2002.pdf>

Li, F.; BIi, J.; Huang, L.; Qu, C.; Yang, J.; Bu, Q. Mapping human vulnerability to chemical accidents in the vicinity of chemical industry park. Journal of Hazardous Materials, 179, 500-506, 2010. doi: 10.1016/j.jhazmat.2010.03.031

Luiz, R. A. F. Análise da vulnerabilidade aos acidentes tecnológicos no entorno do distrito industrial do município de Paulínia. São Paulo, Dissertação (Mestrado em Saúde Pública) - USP, 2013.

Manaus. Lei Complementar n. 002, de 16 de janeiro de 2014. Dispõe sobre o Plano Diretor Urbano e Ambiental do Município de Manaus e dá outras providências. Manaus, 16 jan. 2014.

Martínez-Alegría, R.; Ordoñes, C.; Taboada, J. A conceptual model for analyzing the risks involved in the transportation of hazardous goods: implementation in a Geographic Information System. Human and Ecological Risk Assessment, 9(3), 857-879, 2003. doi: 10.1080/713609970

Mendoza-Cantú, A.; Heydrich, S. C.; Cervantes, I. S.; Orozco, O. O. Identification of environmentally vulnerable areas with priority for prevention and management of pipeline crude oil spills. Journal of Hazards Materials, 92, 17061713, 2011. doi: 10.1016/j.jenvman.2011.02.008

OECD - Organisation for Economic Co-operation and Development. Guiding principles for chemical accident prevention, preparedness and response: guidance for industry (including Management and labour): public authorities, community and others stakeholders. 2. ed. Paris: OECD, 2003.

Otway, H. J. Regulation and risk analysis. In: Otway, H. J.; Peltu, M. (Ed.). Regulating industrial risks: science, hazards and public protection. Londres: Butterworths, p. 1-19, 1985.

Renn, O. Risk analysis: scope and limitations. In: Otway, 
H. J.; Peltu, M. (Ed.). Regulating industrial risks: science, hazards and public protection. Londres: Butterworths, p. 111-127, 1985.

Renn, O. Concepts of risk: a classification. In: Social theories of risk. Londres: Praeger, 1992.

Rocha Jr.; E.; Costa, C. M. C.; Godini, M. D. Acidentes ampliados à luz da "Diretiva Seveso" e da Convenção no 174 da Organização Internacional do Trabalho - OIT. Revista de Gestão Integrada em Saúde do Trabalho e Meio Ambiente, 1(2), Seção 2, 2006. Disponível em: <http://www.revistas. sp.senac.br/index.php/ITF/article/viewFile/441/387>

Rodrigues, J. E. C. Risco tecnológico: uma análise do porto de Vila do Conde como área potencial de ameaça ao vazamento de óleo para comunidades em situação de vulnerabilidade. Belém, Dissertação (Mestrado em Geografia) - UFPA, 2008.

Rosa, A. C. Risco tecnológico em contextos de vulnerabilidade social e ambiental elevados: experiências na região da Refinaria Gabriel Passos/Petrobras, Região Metropolitana de Belo Horizonte, Minas Gerais (1998-2007). Ouro Preto, Dissertação (Mestrado em Engenharia Ambiental) - UFOP, 2008.

SEP/PR - Secretaria de Portos da Presidência da República. Disponível em: < https://webportos.labtrans.ufsc.br/Brasil/ Index $>$. Acesso em abril de 2017.
SEMMAS - Secretaria Municipal de Meio Ambiente e Sustentabilidade de Manaus. Disponível em: <http://semmas. manaus.am.gov.br/about/licencas-expedidas $>$. Acesso em abril de 2017.

Sevá Filho, A. O. No limite dos riscos e da dominação: a politização dos investimos industriais de grande porte. Campinas, Tese (Doutorado em Geografia) - UNICAMP, 1988.

Smith, K.; Petley, D. N. Enviromental hazards: assessing risk and reducing disaster. London: Routledge, 2009.

Tixier, J.; Dandrieux, A.; Dussere, G.; Bubbico, R.; Mazzarotta, B.; Silvetti, B.; Hubert, E.; Rodrigues, N.; Salvi, O. Environmental vulnerability assessment in the vicinity of an industrial site in the frame of ARAMIS European Project. Journal of Hazards Materials, 130, 251-264, 2006. doi: 10.1016/j.jhazmat.2005.07.020

UNISDR - United Nations Office for Disaster Rick Reduction. Living with risk: a global review of disaster reductions initiatives. Geneva: ISDR, 2004. Disponível em: <http:// www.unisdr.org/eng/about_isdr/bd-lwr-2004-eng.htm>. Acesso em outubro de 2016.

Veyret, Y.; Richemond, N. M. O risco, os riscos. In: Veyret, Y. (Org.). Os riscos: o homem como agressor e vítima do meio ambiente. São Paulo: Contexto, p. 23-24, 2007.

Yang, Y.; Ma, J. Study on risk zoning technology of major environmental risk sources in urban scale and its application in Shanghai, China. Procedia Environmental Sciences, 2, 1050-1062, 2010. doi: 10.1016/j.proenv.2010.10.117 